\title{
Role of Local Immunosuppression in Murine Fetoplacental Listeriosis
}

\author{
Raymond W. Redline and Christopher Y. Lu \\ Departments of Medicine (Renal Division) and Pathology, Brigham and Women's Hospital, \\ and Harvard Medical School, Boston, Massachusetts 02115
}

\begin{abstract}
Recent evidence suggests that local immunoregulation may prevent rejection of the placenta by the mother. This local immunoregulation may also compromise the response to placental infection. Listeria monocytogenes infection in 121 pregnant mice and 1,050 fetoplacental units was examined and the kinetics of bacterial growth in various maternal and fetal tissues were determined. A subset of pregnant mice developed overwhelming placental listeria infections. Pregnancy did not impair the maternal immune response in the liver and spleen. Pregnant mice without placental infection had numbers of listeria equivalent to nonpregnant controls and mice immunized during pregnancy had significantly less listeria than nonimmunized controls. The secondary response in immunized pregnant mice had no effect on the development of placental infection and the histologic features of placental infection were distinct from those in other organs. Our data suggest that an ineffective local immune response may contribute to the pathogenicity of listeria for the placenta.
\end{abstract}

\section{Introduction}

Infection of the fetoplacental unit is a major cause of perinatal morbidity and mortality. Listeria monocytogenes is particularly important because of its extreme virulence for the fetus in both human and animal populations. In one study this organism was isolated from $1.6 \%$ of total pregnancy losses over a $4 \frac{1}{2} 2$-yr period (1), and it is a well-known cause of neonatal sepsis (granulomatosis infantiseptica) and meningitis (2).

Infection of the fetoplacental unit is a complex event that involves not only the pathogen, the immature fetal immune system, and the maternal immune response, but also, and perhaps most importantly, the fetal-maternal immunologic relationship. The latter, because of the paternal antigens of the fetus and placenta, may be considered an allograft-host relationship (3).

How the fetoplacental unit survives in the potentially hostile maternal immunologic environment remains a major unsolved problem in immunology. Recent evidence indicates that local immunoregulatory influences at the maternal-fetal interface (the decidua and placenta) are important (4). These include a variety of decidual cells that suppress lymphocyte activation in vitro (5-7), and immunoregulatory properties of the placental cells

Address reprint requests to Dr. Redline, Department of Medicine, Renal Division, Brigham and Women's Hospital, 75 Francis St., Boston, MA 02115.

Received for publication 20 October 1986

J. Clin. Invest.

(c) The American Society for Clinical Investigation, Inc.

0021-9738/87/04/1234/08 \$1.00

Volume 79, April 1987, 1234-1241 themselves (8). Others have suggested that regulation of the maternal immune response at a systemic level may also occur (9-11).

The present studies were designed to test the hypothesis in mice that local immunoregulation at the maternal-fetal interface, which normally prevents the maternal immune response from rejecting the placenta, also prevents the maternal immune system from defending this area from listeria infection. The maternal, and not the fetal, immune response is expected to be the major defense system operating at the maternal-fetal interface. The immature rodent immune system is unable to mount an effective response against intracellular pathogens such as listeria (reviewed in reference 12). Previous investigators (13-15) have focused primarily on the effects of pregnancy on listeria growth in maternal organs and the overall status of the maternal immune response as the determining factors in the outcome of infection. The present study is, to our knowledge, the first to also consider critical local immunoregulatory events and infection at the maternal-fetal interface itself - the placenta and decidua.

We have chosen murine perinatal listeriosis as a model for the following reasons. (a) Listeria monocytogenes is a significant cause of perinatal wastage in many species including humans and rodents (16). (b) Extensive studies using nonpregnant adult mice have defined the mechanisms of host defense against listeria (17-19). (c) An intracellular pathogen such as listeria is particularly appropriate for analyzing local events in the decidua and placenta, since these pathogens resist antibodies made by maternal plasma cells at a distance from the maternal-fetal interface. To destroy intracellular pathogens, lymphocytes and macrophages must actually enter the placenta and uterine decidua, where they may be inhibited by any local regulatory influences. (d) The critical events of listeriosis occur within the first $5 \mathrm{~d}$ of infection. The infection can run its entire clinical course during the brief 19-20-d murine gestation. (e) Hematogenous infection of the fetoplacental unit is thought to occur in both humans and rodents $(2,16)$, making it unnecessary to resort to artificial means such as the direct injection of organisms into the placenta to create a model analogous to the human clinical situation.

Overall, the data in this study are consistent with the hypothesis that the placenta and immediately adjacent tissue is an immunologically privileged site. If infection of this area occurred, bacterial proliferation was overwhelming because it was not accessible to the maternal immune system. Pregnancy itself did not induce systemic immunosuppression.

\section{Methods}

Animals. B10.A/SgSn (listeria-resistant phenotype) $(20,21)$ female and BALB/c ByJ male (listeria-sensitive phenotype) mice (4-8 mo of age) were obtained from Jackson Laboratories, Bar Harbor, ME. Mice were mated overnight. The day that vaginal plugs were detected was called day 1 of pregnancy. Unless otherwise specified, pregnant females were injected with listeria on day 14 of pregnancy and killed at indicated times thereafter. Animals and bacteria were housed and handled in accordance with institutional guidelines. 
Listeria monocytogenes (EGD strain) were passed several times through mice to enhance virulence, frozen in phosphate-buffered saline (PBS) with $20 \%$ glycerol, stored at $-80^{\circ} \mathrm{C}$ at a concentration of 2.2 $\times 10^{7}$ viable organisms per milliliter, and used within $1 \mathrm{yr}$ of freezing. Bacteria were thawed on the day of injection, diluted to the appropriate concentration with filter-sterilized PBS, and injected intravenously in a total volume of $0.5 \mathrm{ml}$. The plating of serial dilutions on brain heart infusion (BHI) ${ }^{1}$ agar (BBL Microbiology Systems, Cockeysville, MD) (BHI plates) confirmed $>95 \%$ viability after storage at $-80^{\circ} \mathrm{C}$. At the time of killing organs were removed in a sterile fashion, placed in $20 \mathrm{ml}$ of filter sterilized PBS- $0.05 \%$ Triton X-100 at $4^{\circ} \mathrm{C}$, and homogenized within $2 \mathrm{~h}$ using a motor-driven teflon pestle and a $50-\mathrm{ml}$ Wheaton glass homogenizer. Serial 10-fold dilutions were plated on duplicate BHI plates and colonies were counted after incubation at room temperature for 48$72 \mathrm{~h}$. The limits of detection of this assay were 100 bacteria per organ. All instruments and glassware were cleaned and flamed with 95\% ethanol between organs to insure sterility. Listeria colonies were identified by virtue of their distinct morphology (pearl-white, translucent, and cone shaped) and periodic gram stains. Occasional colonies of other morphologies were gram stained and tested with polyvalent anti-listeria antisera (Difco Laboratories, Detroit, MI) if necessary. Rare heavily infected animals had a second population of gram-negative rods with large mucoid yellow-white colony morphology. These were felt to represent superinfection by endogenous gastrointestinal flora.

Controls. Age-matched, nonpregnant B10.A female mice were injected with listeria and killed in the same fashion as their pregnant counterparts.

Lethal dose. The term $\mathrm{LD}_{50}$ in this study refers to the dose of intravenous listeria that caused $50 \%$ mortality of either pregnant or agematched, nonpregnant female mice within $5 \mathrm{~d}(120 \mathrm{~h})$ of injection. Effects at time points after $5 \mathrm{~d}$ were not studied.

Pregnancy immunizations. A group of B10.A females mated as above and found to have vaginal plugs on day 1 were injected subcutaneously in the footpads and flanks on day 2-3 of pregnancy with a total of 2 $\times 10^{5}$ listeria in $0.5 \mathrm{ml}$ PBS. They were then either killed or rechallenged intravenously with $2 \times 10^{5}$ listeria on day 14 . Liver, spleen, lungs, placentas, and fetuses were cultured from the animals killed on day 14 to insure that the primary infection had been eliminated. The animals rechallenged on day 14 were killed $72 \mathrm{~h}$ later and compared with nonimmunized animals challenged in the same fashion.

Definitions of organs and reported listeria titres. Spleen, liver, lungs, and the uteri of nonpregnant females were removed intact and homogenized as described above. The term placenta can be defined in several ways. One alternative is to consider only that tissue which is expelled by the mother at the time of parturition. While this is the most common definition it excludes the decidua, an important site where fetal trophoblast and maternal cells are intimately associated. In view of this and the recent evidence of decidual immunoregulatory activity (4), an extended definition was considered appropriate. The tissue referred to as placenta in this study was obtained by incising the uterus along the lateral placental disc margin and removing the fetus and surrounding fetal membranes. It included chorionic plate, labyrinth, spongiotrophoblast, decidua, and a portion of the muscular uterine wall. All subsequent references to placenta or placental infection refer to this tissue.

The placenta was bisected with a sterile razor blade. Half was placed in PBS- $0.05 \%$ Triton X-100 for later homogenization as a pool of all placentas from one pregnant female. The cut surface of the remaining half was carefully blotted onto a BHI plate to assess the presence or absence of listeria in each individual placenta. This tissue was then either discarded, placed in $10 \%$ neutral buffered formalin for routine histologic processing, or snap frozen for later immunocytochemical analysis.

We were interested in visceral infections of the fetus, not surface contamination by bacteria from the adjacent placenta. Fetuses were therefore evaluated as living or dead, killed by cervical pressure, immersed

1. Abbreviations used in this paper: $\mathrm{BHI}$, brain heart infusion; $\mathrm{LD}_{50}$, lethal dose of listeria for $50 \%$ of injected animals. in $95 \%$ ethanol, flamed, and weighed. The internal organ block (thymus, cardiopulmonary system, abdominal organs, gastrointestinal tract, and genitourinary system) was removed with sterile instruments through a Y-shaped ventral incision and carefully blotted onto BHI plates as described above to evaluate infection of individual fetuses. The central nervous system was not evaluated. In some cases the organ blocks were pooled and cultured or placed in $10 \%$ formalin for histologic examination.

The bacterial titres reported refer to the total number of bacteria in each compartment within the pregnant mother (whole organs, the sum total of all placentas, and the internal organs from all fetuses). Because nonreticuloendothelial organs were not homogeneously involved by listeria and because the outcome of pregnancy was likely to be dependent on the total bacterial load in any given compartment, it was considered inappropriate to normalize bacterial titres by weight. This was especially true for placentas and fetal organs where only a fraction of total fetoplacental units have any detectable organisms. All tissue was weighed and the approximate ranges found were as follows: spleen and lungs, 0.2-0.5 g; liver, $1.5-2.0 \mathrm{~g}$; placentas and fetal organs, $1.5-2.5 \mathrm{~g}$. Weight differences therefore varied 3-5-fold. Bacterial titres, as will be demonstrated below, varied 100-10,000 fold.

Statistical methods. The geometric log mean of bacterial titres plus or minus the standard error of the mean was depicted in most of the figures and tables. In comparing immunized to nonimmunized pregnant mice, comparisons of group means were made using the one-tailed unpaired $t$ test.

\section{Results}

Listeria-infected pregnant mice may be divided into two groups based on the presence or absence of placental infection. Fig. 1 shows the number of listeria in the lungs and placenta at various times after an intravenous injection of bacteria. 18-120 h after inoculation there was the gradual emergence of a distinct subgroup of pregnant animals with very large numbers of listeria in their placentas. 4 of 18 mice had $>10^{4}$ bacteria at $18 \mathrm{~h} ; 10$ of $17,>10^{7}$ at $72 \mathrm{~h}$; and 14 of $30,>10^{8}$ at $120 \mathrm{~h}$. The remaining animals had either no detectable organisms $(27 / 37$, threshold of detection $=100$ bacteria) or very low levels of placental listeria. We have arbitrarily chosen $10^{4}$ placental listeria as a cutoff to separate the subgroup with very large numbers of placental listeria (placenta positive) from the remaining animals with no or minimal placental infection (placenta negative). The groups are naturally so well defined that changing the cutoff value would not substantially change the subsequent data analysis.

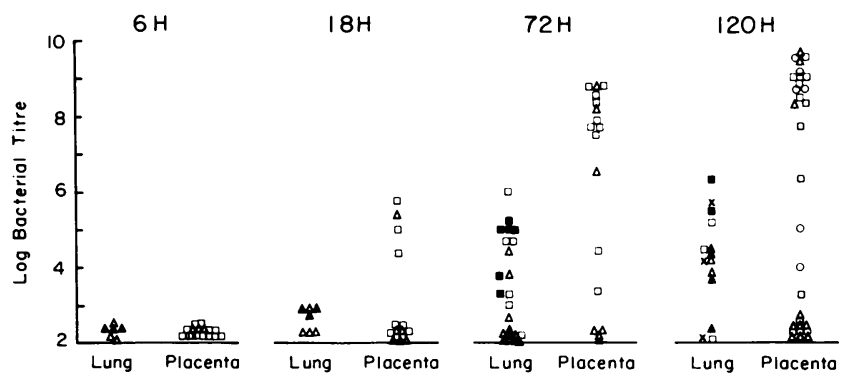

Figure 1. Kinetics of placental and pulmonary infection at various times after intravenous injection of listeria. The ordinate is the $\log _{10}$ of the total bacteria count for pooled placentas and both lungs from individual animals (number of listeria injected: $\Delta, 5 \times 10^{4} ; \circ, 1 \times 10^{5} ; \square, 2$ $\left.\times 10^{5}\right)$. Lung titres from nonpregnant, age-matched females are also displayed (number of listeria injected: $\Delta, 5 \times 10^{4} ; n, 2 \times 10^{5} ; \times, 2$ $\times 10^{6}$ [greater than $\mathrm{LD}_{50}$ ]). The lowest value for bacterial titre on the ordinate, $10^{2}$, represents the threshold of detection of our assay system. 
Table I shows that the proportion of placenta-positive mice at $120 \mathrm{~h}$ was dependent on the number of injected listeria. 10 animals per group were injected with one of three doses of listeria $\left(5 \times 10^{4}, 1 \times 10^{5}\right.$, and $\left.2 \times 10^{5}\right)$ and the proportions of placenta positive were 30,50 , and $90 \%$, respectively. Final placental bacterial titres were, however, independent of the initial inoculum.

Overwhelming bacterial growth in infected placenta. If the placenta was infected, listeria growth at that site was overwhelming. Fig. 1 compares the kinetics of placental versus pulmonary infection. No bacteria were detectable at either site at $6 \mathrm{~h}$ after infection. At each later time point, infected placentas had 100-1,000-fold more organisms than the most heavily infected lungs.

The uterus per se was not a favored site for bacterial growth. No bacteria were cultured from the uteri of nonpregnant females at $6,18,72$, or $120 \mathrm{~h}$ after injection of $5 \times 10^{4}$ listeria (three animals per group). Infection of the uterus could be accomplished with very high inocula (greater than the $\mathrm{LD}_{50}$ ), but even in this setting uterine bacterial titres were always three or more logs below spleen titres. It follows that either the fetoplacental unit or local changes accompanying the pregnant state (decidualization, local mediators) were responsible for the peculiar pattern of placental infection.

A comparison of Figs. 1 and 2 reveals that bacterial growth in infected placentas also differs from that in the liver and spleen. The latter reticuloendothelial organs trapped $\sim 90 \%$ of the initially injected listeria within $10 \mathrm{~min}$, supported bacterial growth to a level of $10^{5}-10^{6}$ per organ from 18 to $72 \mathrm{~h}$, and stabilized or decreased bacterial growth by $120 \mathrm{~h}$. The infected placentas in our model lacked this initial clearance capacity (no organisms at $10 \mathrm{~min}$ ), failed to control proliferation, and attained bacterial titres far in excess of those in any of the spleens or livers tested.

Bacterial growth in the spleen and liver is different in pregnant mice with and without placental infection. Further examination of Fig. 2 shows that the placenta-positive and placenta-negative mice differed in their ability to control splenic and hepatic listeria infection. Bacterial growth at these sites in placenta-negative mice was controlled in the same manner as in age-matched, nonpregnant females. Placenta-positive mice, on the other hand, developed significantly higher splenic and hepatic listeria loads after an injection of $5 \times 10^{4}$ listeria. Similar relationships were seen after injecting 11 pregnant mice with $1 \times 10^{5}$ and 46 pregnant mice with $2 \times 10^{5}$ listeria (data not shown).

Maternal mortality. Fig. 3 compares the mortality rates for pregnant versus age-matched female nonpregnant controls $5 \mathrm{~d}$ after the injection of varying doses of listeria. Considered as a

Table I. Relationship of Placental Infection at $120 \mathrm{~h}$ to the Initial Listeria Dose

\begin{tabular}{llll}
\hline Inoculum & $\begin{array}{l}\text { No. of } \\
\text { pregnant mice }\end{array}$ & $\begin{array}{l}\text { Placenta } \\
\text { positive* }\end{array}$ & $\begin{array}{l}\text { Log mean titre } \\
\text { placenta positive }\end{array}$ \\
\hline $5 \times 10^{4}$ & 10 & 3 & $9.1 \pm 0.49$ \\
$1 \times 10^{5}$ & 10 & 5 & $8.2 \pm 0.75$ \\
$2 \times 10^{5}$ & 10 & 9 & $8.4 \pm 0.34$
\end{tabular}

Pregnant mice were injected with live listeria on day 14 of pregnancy and killed $120 \mathrm{~h}$ later.

* Placenta positive is arbitrarily defined as $>10^{4}$ in the combined placental tissue from one mother.

${ }^{\ddagger}$ Log mean titre \pm SEM for placenta-positive subgroup only.

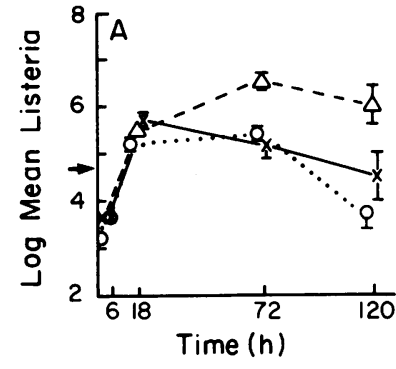

Figure 2. Kinetics of $(A)$ spleen and $(B)$ liver infection at various times after intravenous injection of $5 \times 10^{4}$ listeria. The ordinate is the $\log _{10}$ mean listeria \pm SEM for $\Delta$ placenta positive ( $>10^{4}$ listeria in pooled placentas), 0 placenta negative (less than or equal to $10^{4}$ listeria in pooled placentas), and $(x)$ age-matched, nonpregnant female controls. Symbols closest to the $y$ axis are $\log$ bacterial titres $10 \mathrm{~min}$ after injection. The arrow on the $y$ axis represents the log of the injected dose. All animals were placenta negative at $10 \mathrm{~min}$ and $6 \mathrm{~h}$.

Eight to ten pregnant animals were tested at each time point.

single group, pregnant mice had a lower $\mathrm{LD}_{50}$ than nonpregnant mice. The shape of the mortality curves of pregnant versus nonpregnant mice was different. The mortality curve of nonpregnant mice was sharp-there was a pronounced and marked increase in mortality when $>10^{6}$ bacteria were injected. No nonpregnant mice died at doses $<1 \times 10^{6}$ listeria. The curve of pregnant mice, on the other hand, was shallow. A small number of pregnant mice died, even at bacterial doses several orders of magnitude below the $\mathrm{LD}_{50}$.

The mortality curve for pregnant mice may reflect two subpopulations, mice with and without placenta infections. The incidence of overwhelming placenta infection increased as the number of injected listeria increased. However, at low doses of listeria, occasional animals developed overwhelming placental infection (see Table I). No matter what the injected dose of listeria, once listeria reached the placenta in sufficient numbers, they grew in an uncontrolled manner and severe maternal morbidity and mortality resulted. The shape of the mortality curve

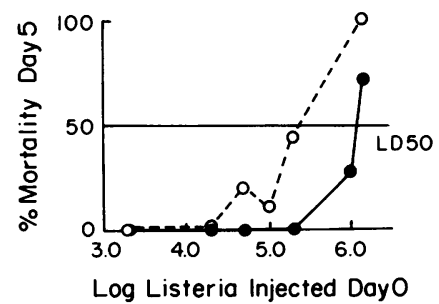

\begin{tabular}{lccccccc} 
Log Inoculum & 3.3 & 4.3 & 4.7 & 5.0 & 5.3 & 6.0 & 6.3 \\
Pregnant & 2 & 1 & 25 & 17 & 18 & 0 & 4 \\
Nonpregnant & 0 & 2 & 6 & 0 & 10 & 11 & 7 \\
& \multicolumn{5}{c}{ No. of Animals Injected }
\end{tabular}

Figure 3. Percent mortality on day $5(120 \mathrm{~h})$ versus the log of the listeria inoculum for (open circle) pregnant and (solid circle) nonpregnant age-matched female mice. The $\mathrm{LD}_{50}$ is represented by a solid horizontal line. The number of animals tested at each dose is tabulated below the figure. All deceased animals were autopsied. Gross evidence of fetoplacental infection was found in 20/20 dead pregnant mice. 
Table II. Development of Infection in

Individual Placentas and Fetuses

\begin{tabular}{lllll}
\hline & $6 \mathrm{~h}$ & $18 \mathrm{~h}$ & $72 \mathrm{~h}$ & $120 \mathrm{~h}$ \\
\hline $\begin{array}{l}\text { Total fetoplacental } \\
\text { units }\end{array}$ & 109 & 94 & 50 & 72 \\
$\begin{array}{l}\text { No. of placentas } \\
\text { positive }\end{array}$ & $1(1)^{*}$ & $7(7)$ & $42(84)$ & $68(94)$ \\
$\begin{array}{l}\text { No. of live fetuses } \\
\text { positive }\end{array}$ & $0(0)$ & $0(0)$ & $12(24)$ & $16(22)$ \\
$\begin{array}{l}\text { No. of macerated/dead } \\
\text { fetuses positive }\end{array}$ & $0(0)$ & $0(0)$ & $6(12)$ & $34(47)$ \\
$\begin{array}{c}\text { No. of total fetuses } \\
\text { positive }\end{array}$ & $0(0)$ & $0(0)$ & $18(36)$ & $50(69)$ \\
\hline
\end{tabular}

Pregnant mice were given an intravenous injection of $2 \times 10^{5}$ listeria and then killed at the indicated times. Touch preps of isolated individual placentas and fetal organs were made on BHI agar plates and scored as positive or negative 48-72 $\mathrm{h}$ later. Percent positive is in parentheses. Fetuses are separated into live and macerated/dead by gross observation at the time of killing.

* One colony detected on one placenta.

* Total fetuses $=$ live + macerated/dead.

in pregnant mice would therefore be a result of the small but significant number of pregnant mice that develop placental infection at doses several logs below the $\mathrm{LD}_{50}$. Supporting this analysis was the observation that all dead pregnant mice, irrespective of the number of injected listeria, had gross evidence of fetoplacental infection (large numbers of degenerating infected gestational sacs).

Placental infection has devastating fetal consequences. Table II shows the involvement of individual placentas and fetuses at various times after the injection of $2 \times 10^{5}$ listeria. Fetal infection developed later than placental infection (72 vs. $18 \mathrm{~h}$ ) and involved a lower percentage of fetoplacental units at all time points. Fetuses were never infected in the absence of placental involvement of the same fetoplacental unit. Table III shows that, although less than placental levels, fetal organ listeria titres rapidly rose to very high levels within a similar time frame. Listeria infection was not limited to morphologically abnormal or nonviable fetuses. The organ blocks of viable macroscopically normal fetuses were positive for listeria (individual viable fetuses in Table

Table III. Log Mean Listeria Titres in Fetal Internal Organs

\begin{tabular}{lccll}
\hline $5 \times 10^{4}$ listeria & $6 \mathrm{~h}$ & $18 \mathrm{~h}$ & $72 \mathrm{~h}$ & $120 \mathrm{~h}$ \\
\hline No. of broods tested & 6 & 8 & 2 & 4 \\
Fetal titre & $<2.0$ & $<2.0$ & $5.8 \pm 1.98$ & $7.1^{*}$ \\
Placenta titre & $<2.3$ & $<2.3$ & $8.5 \pm 0.42$ & $8.3^{*}$ \\
$2 \times 10^{5}$ listeria & $6 \mathrm{~h}$ & $18 \mathrm{~h}$ & $72 \mathrm{~h}$ & $120 \mathrm{~h}$ \\
\hline No. of broods tested & 10 & 10 & 3 & $\mathrm{ND}$ \\
Fetal titre & $<2.0$ & $<2.0$ & $7.3 \pm 0.52$ & - \\
Placenta titre & $<2.3$ & $<2.3$ & $8.1 \pm 0.67$ & - \\
\hline
\end{tabular}

Log mean listeria $( \pm$ SEM) in pooled fetal organs from individual mothers.

* Pool of the internal organs and placentas from four pregnant mice.

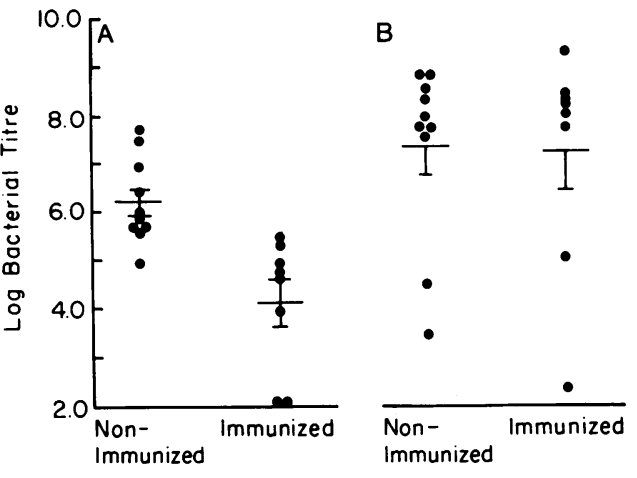

Figure 4 . The effect of early pregnancy immunization on listeria infection. Individual $\log$ spleen $(A)$ and placenta $(B)$ bacterial titres $72 \mathrm{~h}$ after intravenous injection of $2 \times 10^{5}$ listeria on day 14 of pregnancy for nonimmunized and immunized mice. The immunization consisted of injecting $2 \times 10^{5}$ live listeria subcutaneously into the flanks and footpads on day 2-3 of gestation. Six immunized animals killed on day 14 without rechallenge had no detectable organisms in spleen, liver, lung, placentas, or fetuses. Mean \pm SEM is shown $(P<0.005$ spleen, immunized versus nonimmunized, no significant difference for placentas; one-tailed unpaired $t$ tests).

II). Macerated fetuses, defined here as necrotic, purulent, nonviable, and heavily infested with listeria, were observed at a still later time. The progression from placental infection to internal infection of viable fetuses and later to nonviable macerated fetuses suggests that infection of the fetus occurs during the course of placental infection and is not merely a consequence of fetal death and subsequent colonization.

Pregnant mice may be successfully immunized. 17 pregnant mice were immunized on day 2-3 of gestation by injecting 2 $\times 10^{5}$ listeria into the flanks and footpads. Three succumbed, presumably to infection, within the first week. Six animals were killed $12 \mathrm{~d}$ later on day 14 of gestation and no evidence of persistent infection was found in the spleens, livers, lungs, or placentas. The remaining eight animals were challenged intravenously with $2 \times 10^{5}$ listeria on day 14 , killed $72 \mathrm{~h}$ later, and compared with nonimmunized animals receiving the same number of intravenous listeria. Fig. 4 demonstrates bacterial counts in the spleen and placenta. Table IV shows characteristics of the fetoplacental infections. Two points are apparent. First, mice could be successfully immunized during pregnancy. Immunized mice not only had significantly fewer organisms in their spleens than nonimmunized controls, but had already low-

Table IV. Fetoplacental Infection in Pregnancy Immunized Versus Nonimmunized Pregnant Mice $72 \mathrm{~h}$ after Rechallenge

\begin{tabular}{lcc}
\hline & Nonimmunized $(n=10)$ & Immunized $(n=8)$ \\
\hline Placenta-positive mothers & $9 / 10(90)$ & $7 / 8(88)$ \\
Individual placentas positive* & $42 / 50(84)$ & $53 / 69(77)$ \\
Mothers with infected fetuses & $6 / 7(86)$ & $4 / 4(100)$ \\
Individual fetuses positive* & $18 / 50(36)$ & $7 / 22(32)$
\end{tabular}

Pregnant mice immunized on day 2-3 of gestation, challenged with $2 \times 10^{5}$ listeria on day 14 , and killed on day 17 (see Methods).

* Number positive/total tested (percent positive in parentheses). 
ered their splenic bacteria level to below that of the initial inoculum in 9 of 10 cases, compared with just 1 of 8 cases in the nonimmunized, age-matched control group. In fact two immunized animals had no detectable splenic bacteria. Second, immunization had no effect on the magnitude of placental infection (Table IV) in terms of the bacterial count, the number of mice with placental infection, or the number of placentas and fetuses infected. These observations suggest that even a secondary immune response was unable to influence the course of placental infection.

Histology of placental listeriosis. Before describing our findings, a brief description of the murine placenta may be helpful. Moving from the fetus towards the muscular wall of the uterus, the placenta is composed of four important regions: $(a)$ chorionic plate, fetally derived and containing only fetal blood; $(b)$ labyrinth, fetally derived but containing both fetal and maternal blood, always separated by trophoblast; (c) spongiotrophoblast, fetally derived but perfused only by maternal blood; and $(d)$ decidua, a pregnancy-associated maternal tissue containing scattered fetal trophoblast but no fetal blood.

The inflammatory response to listeria in normal adult tissues is characterized by well-circumscribed granulomas composed predominantly of mononuclear cells ( $T$ cells and macrophages) $(17,22)$. These typical findings were observed in the spleen, liver, and lungs of pregnant females whose fetoplacental units showed a very different histology (Fig. 5). There was a diffuse neutrophilic infiltration of the lower decidua. In cases where bacteria were observed within trophoblast or other fetally derived tissues, there was a notable absence of any inflammatory response. Infected fetal organs also demonstrated an inability to localize bacteria in granulomatous foci (not shown). Overall, the histology suggested an ineffective response to listeria in the placenta. Further characterization of the inflammatory responses is in progress using snap-frozen tissue and immunocytochemical techniques.

\section{Discussion}

The mechanisms by which the fetoplacental unit survives as a natural allograft are of both theoretical and practical interest. Recent evidence suggests that local regulation in the decidua and placenta may be important in preventing rejection of the fetus by the maternal immune response $(23,24)$. The experiments in this report were designed to test the hypothesis that local immunoregulation at the maternal-fetal interface prevents the immune system from defending this area from listeria infection. The experiments reported here are, to our knowledge, the first to focus on infection and local immunoregulation in the placenta. Listeria monocytogenes was chosen as the experimental pathogen not only because it is known to cause fetoplacental infections $(16,25)$, but also because an effective host defense against this intracellular pathogen would require lymphocytes and macrophages to enter the placental region where these cells might be influenced by the putative local immunoregulatory mechanisms (17).

Our data shows that a subset of pregnant mice developed overwhelming placental infection after an intravenous injection of listeria. By $120 \mathrm{~h}$ after injection listeria counts were 100 10,000 times higher than in any maternal organ. Histologic studies showed that the inflammatory response in the placenta was unique. Instead of the well circumscribed, predominantly mononuclear cell granulomas seen in other maternal organs from the same animal, there was a diffuse, predominantly neutrophilic exudate in paraplacental tissues and little or no inflammatory response to organisms located within the placenta itself. Fetal infection developed after placental infection. Fetuses rapidly developed high bacterial loads and succumbed.

There are several explanations for the uncontrolled growth of listeria in the murine placenta. Preferential localization of listeria to the placenta (tropism) was ruled out on the basis of kinetic studies that showed essentially no organisms $6 \mathrm{~h}$ after injection and only 9 of 72 placentas with bacteria at $18 \mathrm{~h}$. Animals injected late in pregnancy (day 18-19) also had no detectable placental organisms at $6 \mathrm{~h}$, showing that there is no change in placental tropism later in gestation (a possible explanation for the late onset of infection in our model). This explanation also fails to account for the striking absence of an appropriate local immune response seen on histologic examination of infected placentas. Two hypotheses encompass all of the available data. Listeria may enter compartments within the placenta that are inaccessible to inflammatory cells, and/or the function of the inflammatory cells themselves may be impaired.

The labyrinthine trophoblast is composed of three cell layers specialized in the transport of materials to the fetus (26). If bacteria are able to cross into fetal spaces the immature fetal immune response is poorly equipped to mount an effective defense against them (12). The trilaminar trophoblast has tight intercellular junctions and is unlikely to admit maternal cells. Indeed the survival of the fetal allograft may depend in part on this barrier separating maternal cells from fetal antigens. Furthermore, trophoblast has been reported to have phagocytic properties (27). It may sequester listeria but lack the biochemical machinery to efficiently kill the organism. Experiments in our laboratory using isolated fractionated placental cells are in progress to test the ability of trophoblast to bind, internalize, and kill listeria in vitro. Since trophoblast has been shown not to express class II major histocompatibility complex antigens both in vivo (28) and when cultured in vitro with high doses of gamma interferon (29), it is unlikely to present antigen to either maternal or fetal $\mathrm{T}$ lymphocytes.

The final hypothesis suggests that maternal effector cells are actively prevented from responding to listeria in the placenta. Alpha fetoprotein, present locally at high concentrations, has been shown to inhibit the macrophage functions important in the defense against listeria (30). Decidual cells have been demonstrated to inhibit lymphocyte activation either by secreting macromolecules which inhibit the response to interleukin 2 (5) or by secreting prostaglandin $\mathrm{E}_{2}(7)$, a known inhibitor of lymphocyte mitogenesis as well as macrophage functions (31). Trophoblast has been shown, under some circumstances, to inhibit the effector function of natural killer cells and $T$ lymphocytes $(8,32)$. The effect of trophoblast and decidual cells on $T$ lymphocyte and macrophage functions known to be important in the defense against listeria are being actively investigated in our laboratory.

Overall, we believe that the data favor a model in which small variable numbers of listeria seed the placenta during the course of infection. The placenta may only be able to contain the growth of minimal numbers of listeria-below the limits of detection (100 bacteria per organ) of our assay system. If this threshold is exceeded, overwhelming proliferation results. This would explain why bacterial numbers in the placenta were either very low or very high (see Fig. 1). According to this hypothesis, the number of listeria in the initial inoculum should determine 

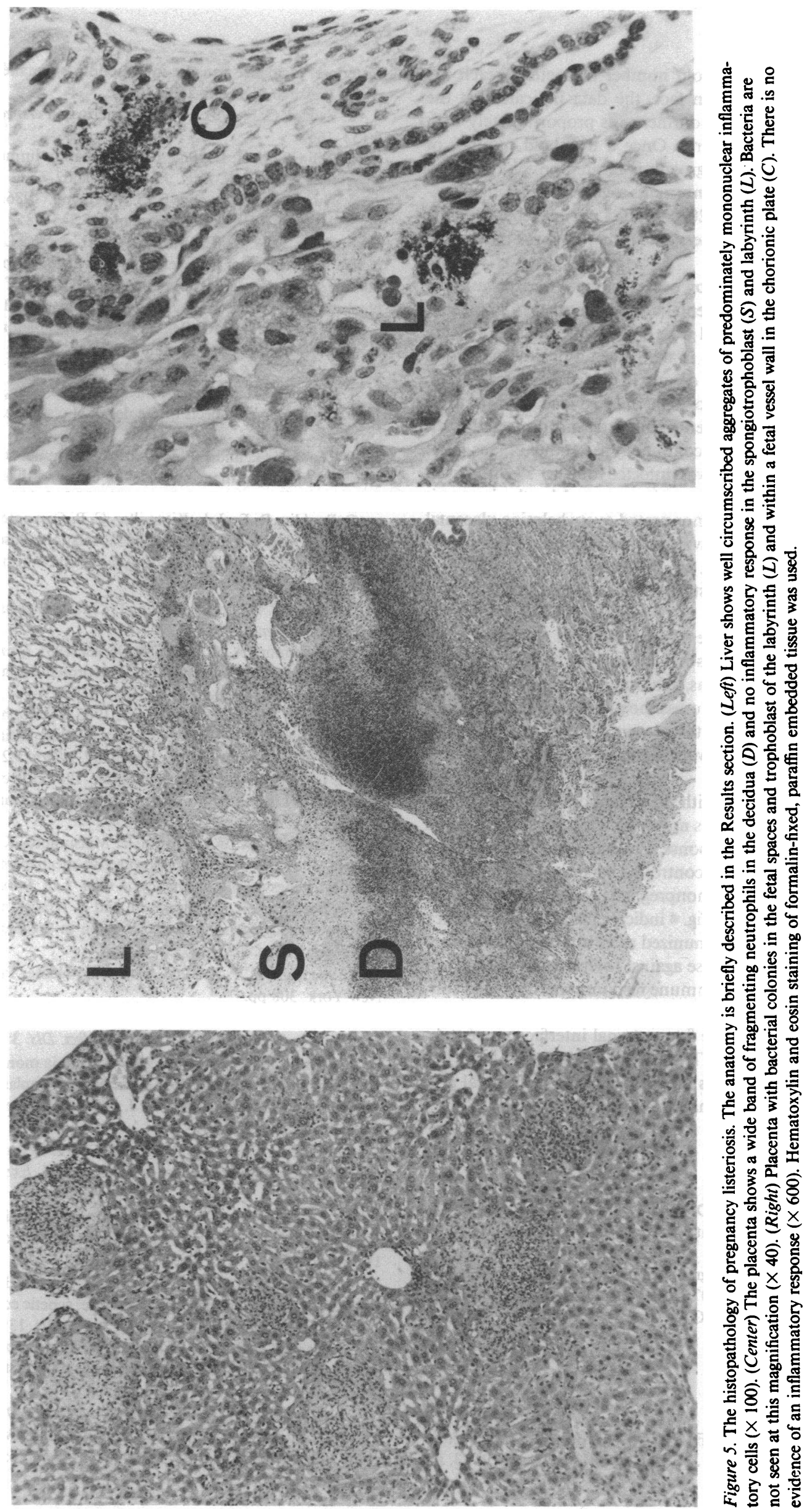
the probability that a threshold number of bacteria reach the placenta by chance alone. In fact, the data indicate that the incidence of placental infection increases proportionately with the number of injected listeria. Once a threshold number of bacteria reach the placenta, growth is limited only by physical factors such as exhaustion of nutrients, overcrowding, etc. Maximum bacterial counts at $120 \mathrm{~h}$ should not be related to the injected dose of listeria. Table I shows that this was indeed the case.

If placental listeria infection occurred, there were devastating consequences for the fetoplacental unit and mother. All pregnant mice dying after listeriosis had gross pathologic evidence of severe fetoplacental infection. Mice in the placenta-positive subgroup (Fig. 2) had higher bacterial counts in their spleens and livers than nonpregnant control mice. The infected placenta may exert its detrimental effects by offering the listeria a protected environment from which it could continually seed other organs. That placentas were not themselves infected due to seeding from heavily infected spleens or livers is suggested by the immunization experiments which demonstrated overwhelming placental infection despite very low levels of listeria in maternal reticuloendothelial organs (see Fig. 4).

The placenta did not constitute an effective barrier to protect the fetus from infection, but the percentage of infected fetuses lagged well behind the percentage of infected placentas at all time points. Individual fetuses were never positive in the absence of infection in their placentas, making it unlikely that, as has been suggested (16), bacteria cross the placenta, infect the fetus, and later secondarily infect the placenta. Fetal bacterial titres were the same or slightly lower than placental titres at all time points tested.

Our data indicate that, with the exception of the immediate placental area, pregnancy does not cause widespread suppression of the maternal immune response. Pregnant mice without large numbers of placental listeria controlled bacterial growth in their spleens and livers as well as nonpregnant control mice (see Fig. 2). Furthermore, the data in Fig. 4 indicate that during pregnancy mice may be successfully immunized against listeria. These mice mounted a secondary response against listeria in the spleen, but even a secondary maternal immune response was unable to control listeria proliferation in the placenta. It therefore appears likely that local events at the fetomaternal interface prevent an effective immune response. These may be the same local immunoregulatory mechanisms that protect the fetoplacental unit from rejection by the maternal immune system.

\section{Acknowledgments}

We thank Dr. Ramzi Cotran, Dr. Shirley Driscoll, and Dr. Barry M. Brenner for their encouragement and support, and Michelle Herry for her secretarial assistance.

This work was supported by grants from National Institutes of Health RO-1-HD-20188 and 7T32AM-07527-01) and the March of Dimes Birth Defects Research Foundation. C. Y. Lu is a Fellow of the Hartford Foundation.

\section{References}

1. Giraud, J. R., F. Denis, F. Gargot, T. Fizazi, Ph. Babin, Y. de Rautlin de la Roy, A. Hoppeler, J. Brisou, and H. de Tourris. 1973. La
Listériose. Incidence dans les interruptions spontanées de la grossesse. Nouv. Presse Méd. 2:215-218.

2. Vawter, G. F. 1981. Perinatal listeriosis. Perspect. Pediatr. Pathol. 6:153-166.

3. Billingham, R. E. 1964. Transplantation immunity and the maternal-fetal relation. N. Engl. J. Med. 270:667-672.

4. Hunziker, R. D., and T. G. Wegmann. 1986. Placental immunoregulation. CRC Crit. Rev. Immunol. 6:245-285.

5. Clark, D. A., A. Chaput, C. Walker, and K. L. Rosenthal. 1985. Active suppression of host versus graft reaction in pregnant mice. VI. Soluble suppressor activity obtained from decidua of allopregnant mice blocks the response to IL-2. J. Immunol. 134:1659-1664.

6. Badet, M. T., S. C. Bell, and W. D. Billington. 1983. Immunoregulatory activity of supernatants from short-term cultures of mouse decidual tissue. J. Reprod. Fertil. 68:351-358.

7. Lala, P. K., R. S. Parhar, M. Kearns, S. Johnson, and J. M. Scodras. 1986. Immunologic aspects of the decidual response. J. Reprod. Fertil. (Abstr.)

8. Chaouat, G., and J. P. Kolb. 1985. Immunoactive products of the placenta. IV. Impairment by placental cells and their products of CTL function at effector stage. J. Immunol. 135:215-222.

9. Rocklin, R. E., J. L. Kitzmiller, C. B. Carpenter, M. R. Garovoy, and J. R. David. 1976. Maternal-fetal relation. Absence of an immunologic blocking factor from the serum of women with chronic abortions. N. Engl. J. Med. 295:1209-1213.

10. Beer, A. E., and J. O. Sio. 1982. Placenta as an immunologic barrier. Biol. Reprod. 26:15-27.

11. Muchmore, A. V., and J. M. Decker. 1985. Uromodulin: a unique 85-kilodalton immunosuppressive glycoprotein isolated from urine of pregnant women. Science (Wash. DC). 229:479-481.

12. Lu, C. Y., and E. R. Unanue. 1985. Macrophage ontogeny: implications for host defense, T-lymphocyte differentiation, and the acquisition of self-tolerance. Clin. Immunol. Allerg. 5:253-269.

13. Luft, B. J., and J. S. Remington. 1982. Effect of pregnancy on resistance to Listeria monocytogenes and Toxoplasma gondii infections in mice. Infect. Immun. 38:1164-1171.

14. Hamada, M., A. Kuroiwa, T. Matsumoto, K. Nomoto, and K. Takeya. 1981. Modification of protective mechanisms against Listeria monocytogenes during pregnancy. J. Clin. Lab. Immunol. 6:169-173.

15. Bortolussi, R., N. Campbell, and V. Krause. 1984. Dynamics of Listeria monocytogenes type $4 \mathrm{~b}$ infection in pregnant and infant rats. Clin. Invest. Med. 7:273-279.

16. Seeliger, H. P. R. 1961. Listeriosis. Hafner Publishing Co. Inc., New York. 308 pp.

17. Hahn, H. and S. H. E. Kaufmann. 1981. The role of cell-mediated immunity in bacterial infections. Rev. Infect. Dis. 3:1221-1250.

18. North, R. J. 1981. Immunity of Listeria monocytogenes. In Immunology of Human Infection. I. Bacteria, Mycoplasmae, Chlamydiae, and Fungi. A. J. Nahmias and R. J. O'Reilly, editors. Plenum Medical Book Co., New York. 201-219.

19. Lane, F. C., and E. R. Unanue. 1972. Requirement of thymus (T) lymphocytes for resistance to listeriosis. J. Exp. Med. 135:11041112.

20. Cheers, C., and I. F. C. McKenzie. 1978. Resistance and susceptibility of mice to bacterial infection: genetics of listeriosis. Infect. Immun. 19:755-762.

21. Skamene, E., P. A. L. Kongshavn, and D. H. Sachs. 1979. Resistance to Listeria monocytogenes in mice: genetic control by genes that are not linked to the H-2 complex. J. Infect. Dis. 139:228-234.

22. Mandel, T. E., and C. Cheers. 1980. Resistance and susceptibility of mice to bacterial infection: histopathology of listeriosis in resistant and sensitive strains. Infect. Immun. 30:851-861.

23. Croy, B. A., J. Rossant, and D. A. Clark. 1982. Histologic and immunologic studies of post implantation death of Mus caroli embryos in the Mus musculus uterus. J. Reprod. Immunol. 4:277-293. 
24. Clark, D. A., A. Chaput, and D. Tutlon. 1986. Active suppression of host versus graft reaction in pregnant mice. VII. Spontaneous abortion of allogeneic $\mathrm{CBA} / \mathrm{J} \times \mathrm{DBA} / 2$ fetuses in the uterus of $\mathrm{CBA} / \mathrm{J}$ mice correlates with deficient non-T suppressor cell activity. J. Immunol. 136: 1668-1675.

25. Driscoll, S. G. 1962. Congenital listeriosis: diagnosis from placental studies. Obstet. Gynecol. 20:216-220.

26. Enders, A. C. 1965. A comparative study of the fine structure of the trophoblast in several hemochorial placentas. Am. J. Anat. 116:2968.

27. Kaufman, M. H. 1983. The origin, properties, and fate of trophoblast in the mouse. In Biology of Trophoblast. Y. W. Loke and A. Whyte, editors. Elsevier Science Publishers, Amsterdam. 23-68.

28. Chatterjee-Hasrouni, S., and P. K. Lala. 1981. MHC antigens on mouse trophoblast cells: paucity of 1a antigens despite the presence of H-2K and D. J. Immunol. 127:2070-2073.

29. Anderson, D. J., and R. S. Berkowitz. 1985. Gamma interferon enhances expression of class $1 \mathrm{MHC}$ antigens in the weakly HLA+ human choriocarcinoma cell line BeWo, but does not induce MHC expression in the HLA-choriocarcinoma cell line Jar. J. Immunol. 135:2498-2501.

30. Lu, C. Y., P. S. Changelian, and E. R. Unanue. 1984. Alpha fetoprotein inhibits macrophage expression of Ia antigens. J. Immunol. 132:1722-1727.

31. Snyder, D. S., D. I. Beller, and E. R. Unanue. 1982. Prostaglandins modulate macrophage Ia expression. Nature (Lond). 299:163-165.

32. Chaouat, G., J. P. Kolb, and D. Lankar. 1986. Functional and biochemical characterization of NK and CTL inhibiting factors (NKIF) and CTL-IF) from murine placenta. J. Reprod. Immunol. (Abstr.) 